\title{
IMPACTOS AMBIENTAIS \\ DECORRENTES DO PROCESSO DE INSTALAÇÃO E OPERACIONALIZAÇÃO DA USINA DE BIOGÁS GNR DE FORTALEZA (CE): A EDUCAÇÃO AMBIENTAL COMO VIA DE TRANSFORMAÇÃO SOCIAL
}

\author{
Maria Laudecy Ferreira de Carvalho ${ }^{1}$ \\ Joel Silva dos Santos ${ }^{2}$ \\ Luan Gomes dos Santos de Oliveira ${ }^{3}$ \\ Ana Bárbara de Araújo Nunes ${ }^{4}$
}

Resumo: O objetivo deste artigo é identificar os impactos ambientais positivos e negativos causados pela instalação e operacionalização do Aterro SanitárioASMOC e da usina de biogás GNR Fortaleza, localizados no município de Caucaia/CE. A metodologia pautou-se em revisão de literatura, análise documental, entrevistas e questionários, visitas de campo e o uso da Matriz de Leopold para a identificação dos impactos ambientais locais e caracterização da área de estudo. Os resultados obtidos sinalizaram que existem impactos positivos a exemplo da produção do biometano e negativos a exemplo da morte das plantas nativas. Faz- se necessário ações de Educação Ambiental com os atores sociais visando mitigar os impactos ambientais negativos.

Palavras-chave: Impactos Ambientais; Resíduos Sólidos; Biogás.

\footnotetext{
1 Universidade Federal da Paraíba. E-mail: laudecyferreira@gmail.com Link para o Lattes: http://lattes.cnpq.br/0973428133928515

2 Universidade Federal da Paraíba. E-mail: joelgrafia.santos@gmail.com Link para o Lattes: http://lattes.cnpq.br/0301323036214729

3 Universidade Federal de Campina Grande. E- mail: luangomessantos@terra.com.br Link para o Lattes: http://lattes.cnpq.br/2784352958535431

${ }^{4}$ Universidade Federal do Ceará. E-mail: abarbara@deha.ufc.br Link para o Lattes: http://lattes.cnpq.br/1624361530002492
} 
Abstract: The objective of this article is to identify the positive and negative environmental impacts caused by the installation and operation of the Sanitary Landfill-ASMOC and the GNR Fortaleza biogas plant, located in the municipality of Caucaia/CE. The methodology was based on literature review, document analysis, interviews and questionnaires, field visits and the use of the Leopold Matrix to identify local environmental impacts and characterize the study area. The results obtained signaled that there are positive impacts, such as the production of biomethane, and negative ones, such as the death of native plants. Environmental education actions with social actors are needed to mitigate negative environmental impacts.

Keywords: Environmental impacts; Solid Waste; Biogas.

\section{Introdução}

O Brasil tem sinalizado o grande potencial que tem na produção de resíduos sólidos urbanos (RSU), em função do aumento significativo da população brasileira nas últimas décadas em áreas urbanas (ESMAEILIAN et al., 2018; CENTRULO et al., 2020). De acordo com os dados do Instituto Brasileiro de Geografia e Estatística (IBGE), a estimativa da população brasileira é de 210. 546.437 habitantes, em 2019. No Estado do Ceará essa estimativa é de 9. 146. 596 hab. e no município de Caucaia é de 361.400hab (IBGE, 2019) e na cidade de Fortaleza áreas de estudo desta pesquisa, a estimativa é de 2.669.342 habitantes (IBGE, 2019). Além disso, a questão dos RSU se aprofunda enquanto expressão da questão social nos meandros do capitalismo contemporâneo, que programa a descartabilidade das mercadorias, acirra as desigualdades sociais e o desemprego estrutural (ZANETTI, 2009).

De acordo com estudos da Associação Brasileira de Empresas de Limpeza Pública e Resíduos Especiais (ABRELPE, 2018), "no Brasil, cada pessoa gerou $378 \mathrm{~kg}$ de resíduos em 2017”. A ABRELPE, enfatiza que o volume de lixo descartado em lixões seria o suficiente para "encher 160 estádios de futebol semelhante ao Maracanã". Diante desse cenário, os dados da ABRELPE destacam que cada brasileiro produziu mais lixo em 2017 do que em anos anteriores. Para Carlos Silva Pinto presidente da ABRELPE, "a geração de resíduos aumentou em todas as regiões do Brasil e o crescimento na geração per capita foi superior à variação do PIB per capita". Nesse sentido, pode-se afirmar que, o "povo brasileiro passou a descartar mais materiais nos últimos anos". O descarte dos RSU em aterros sanitários aumentou $1 \%$ e os descartes em aterros controlados e lixões passaram dos 29 milhões de toneladas no ano de 2017 em relação aos últimos três anos. Essa quantidade de toneladas, seria suficiente para cobrir uma área equivalente a 600 Parques do Ibirapuera, em São Paulo. Isso equivale a 3\% do aumento na produção de resíduos sólidos, quando relacionado ao ano de 2016 (ABRELPE, 2018).

O aumento da produção de resíduos sólidos, acarreta elevada variação e diversidade na composição dos mesmos o que leva a comprometer a sustentabilidade nos aspectos sociais e de gestão pública e privada. Dentre os 
sistemas ambientais mais afetados pelo descarte dos RSU, o sistema atmosférico é afetado pelos gases de efeito estufa. Dessa forma, medidas urgentes de mitigação e de descarte de lixo devem ser tomadas pelos municípios brasileiros (BURNLEY, 2007; GUERRERO et al., 2013).

Vale destacar, que os resíduos orgânicos são responsáveis por cerca de $76 \%$ de todo gás de efeito estufa emitido no ar, somado aos $19 \%$ das emissões estimadas pela degradação dos papéis e papelões, tornando-se grandes responsáveis pela geração de gás metano $\left(\mathrm{CH}_{4}\right)$.Vale salientar que, por meio da combustão, o gás metano torna-se 21 vezes mais poluente quando comparado ao dióxido de carbono ( $\left(\mathrm{CO}_{2}\right)$ (ABRELPE, 2020; CASTRO; MATEUS, 2016; SOUZA et al., 2019).

Com a grande elevação da emissão de gases de efeito estufa e outros impactos ambientais provenientes do descarte inadequado dos resíduos sólidos, faz -se necessário estudos de impactos ambientais que possam auxiliar os gestores públicos e privados no enfrentamento dessa problemática nos municípios. De acordo com a resolução CONAMA № 001/86 (Conselho Nacional do Meio Ambiente), no seu Art. 1ํㅡ, incisos do I ao V, considera-se Impactos Ambientais como sendo:

"qualquer alteração das propriedades físicas, químicas e biológicas do meio ambiente, causada por qualquer forma de matéria ou energia resultante das atividades humanas que, direta ou indiretamente, afetam:

I - a saúde, a segurança e o bem-estar da população;

II - as atividades sociais e econômicas;

III - a biota;

IV - as condições estéticas e sanitárias do meio ambiente;

$\mathrm{V}$ - a qualidade dos recursos ambientais."

Portanto, a resolução CONAMA 001/86 estabelece a obrigatoriedade do estudo de impacto ambiental para o licenciamento de atividades modificadoras do meio ambiente, além de definir os critérios básicos e as diretrizes gerais para a avaliação de impacto ambiental.

Ainda, a Constituição Federal Brasileira/88 (BRASIL, 1988), promulgada em 05 de outubro de 1988, contempla a questão ambiental de forma direta em seu artigo 225, na qual, afirma em seu caput que:

Todos têm direito ao meio ambiente ecologicamente equilibrado, bem de uso comum do povo e essencial à sadia qualidade de vida, impondo-se ao poder público e à coletividade o dever de defendê-lo e preservá-lo para as presentes e futuras gerações (BRASIL, 1988). 
Os impactos ambientais provenientes da instalação e operacionalização das usinas de biogás instaladas em aterros sanitários devem ser avaliados durante todas as fases da usina desde a instalação à operacionalização. É necessário que tal atividade econômica possa ter os riscos minimizados através da adoção das recomendações e determinações do órgão ambiental responsável pelo licenciamento ambiental na região (SÁNCHEZ, 2008).

Diante desse contexto, vale destacar que o Brasil assumiu 0 compromisso de reduzir emissões de metano e deixar de usar prioritariamente fontes de energia fóssil como o petróleo, de acordo com o Tratado de Kyoto desde 1997. Nesse sentido, propostas de gestão de resíduos por meio da otimização de aterros sanitários com aproveitamento do gás devem ser estudadas e/ou pesquisadas, a exemplo da usina de biogás GNR - Gás Natural Renovável - Fortaleza Valorização de Biogás LTDA., que produz biogás / biometano por meio dos resíduos sólidos urbanos do Aterro Sanitário Metropolitano Oeste de Caucaia, no município de Caucaia região metropolitana de Fortaleza/ Ceará foco deste estudo.

O lixo descartado em aterro sanitário tem sinalizado como mola propulsora dessa nova atividade econômica no Brasil: a produção de biogás, energia renovável, gerada a partir da decomposição natural dos resíduos sólidos em aterros sanitários além de mitigar os gases de efeito estufa se constituem em uma promissora atividade econômica para o país.

Vale destacar que o biogás se define como produto da decomposição anaeróbia, ou seja, ausência de oxigênio gasoso da matéria orgânica, que ocorre por meio da ação de bactérias. A composição do biogás, depende do material orgânico utilizado, assim como do tipo de tratamento anaeróbio que sofre. Esse processo se dá em três fases: Liquefação ou hidrólise, ácida e Gaseificação ou metanogênese. Portanto, a mistura gasosa originada da decomposição do lixo urbano, apresenta os principais gases que compõem o biogás: Metano representado pela fórmula química $\mathrm{CH}_{4} \mathrm{e}$ com volume de gás produzido em $50 \%-70 \%$, assim como Dióxido de Carbono/Gás carbônico $\mathrm{CO}_{2}$ $(25 \%-50 \%)$, Oxigênio $\mathrm{O}_{2}(0 \%-2 \%)$, Nitrogênio $\mathrm{N}_{2}(0 \%-7 \%)$, Hidrogênio $\mathrm{H}_{2}$ $(0 \%-1 \%)$, Gás Sulfídrico $\mathrm{H}_{2} \mathrm{~S}(0 \%-3 \%)$ ) e Amoníaco $\mathrm{NH}_{3}(0 \%-1 \%)$ (MAGALHÃES, 1986; CETESB, 2020).

Singapura no Continente Asiático e outros país no mundo têm modelos eficientes, eficazes e efetivos da política e tratamento dado aos resíduos sólidos urbanos e domiciliares (CARVALHO, 2016)

No Brasil, a região Sudeste tem a maior quantidade de usinas de biogás instaladas em aterros sanitários, assim como maior produtividade de energia elétrica e combustíveis de gás natural renovável provenientes dessas usinas (CETESB, 2020).

A primeira iniciativa de aproveitamento de biogás para produzir biometano ocorreu na década de 1970, no município do Rio de Janeiro no antigo lixão do Caju, e foi operacionalizado entre 1935 e 1977 com 
aproximadamente 30 milhões de metros cúbicos de RSU em uma área de um milhão de metros quadrados, sob a competência da Companhia Municipal de Limpeza Urbana do Estado do Rio de Janeiro (COMLURB) (CEG) (MUYLAERT, 2000).

Em 2014, ainda no município do Rio de Janeiro -RJ, surgiram mais duas usinas de produção de biometano por meio dos resíduos sólidos: a Usina de Gás Verde Gramacho, operada pela Gás Verde S.A., que passou enviar diariamente cerca de 49 mil metros cúbicos de biometano à Refinaria Duque de Caxias (REDUC) e a Usina de Tratamento de Biogás Dois Arcos, operada pelas empresas OSAFI e Ecometano com produção média de oito mil metros cúbicos diários de biometano (SBERA, 2015).

Outra iniciativa de produção de biogás no Brasil surge no Aterro Sanitário Municipal Bandeirantes em São Paulo-SP, em janeiro de 2004, onde foi instalada a Central Termelétrica Biogás de 20MW, que proporciona a geração de mais de $170.000 \mathrm{MWh}$ de energia elétrica, o suficiente para abastecer uma cidade de 400 mil habitantes, por meio do tratamento do lixo e o isolamento do metano e com isso reduzir a emissão equivalente a 8 milhões de toneladas de gás carbono no período de 15 anos (CETESB, 2004, 2020).

$\mathrm{Na}$ região Nordeste do Brasil, o município de Caucaia no Estado do Ceará, destaca-se pela implantação da usina de biometano Gás Natural Renovável - GNR Fortaleza Valorização de Biogás LTDA, que é pioneira na Região Nordeste por produzir biogás a partir do lixo do Aterro Sanitário (ASMOC). Essa usina também é considerada a primeira do Nordeste a distribuir gás renovável para indústrias, comércios e residências, por meio da Companhia de Gás do Ceará (Cegás). A usina GNR tem o objetivo de mitigar os gases de efeito estufa e produzir e vender o biometano.

Para cuidar dos resíduos gerados diariamente, ações de Educação Ambiental devem fazer parte do dia a dia das pessoas, a exemplo de separar os resíduos sólidos na fonte geradora e fazer seu descarte de forma ambientalmente adequado, assim como reutilizar, reciclar e reduzir, dentre outras ações.

É diante desse cenário que surge este trabalho de pesquisa com objetivo principal de identificar os impactos ambientais positivos e negativos causados pela instalação e operacionalização do aterro sanitário do ASMOC e da usina de biogás GNR localizadas no município de Caucaia na região metropolitana de Fortaleza /Ceará, tendo como estratégia de mitigação desses impactos a Educação Ambiental numa perspectiva transformadora. 


\section{Metodologia}

\section{Localização e caracterização da área de estudo: Município de Caucaia - região metropolitana de Fortaleza - Ceará}

A cidade de Fortaleza no Estado do Ceará está localizada na porção Nordeste do Estado, nas coordenadas de Latitude Sul: $3^{\circ} 43^{\prime} 2^{\prime \prime}$ e Longitude Oeste: $38^{\circ} 32^{\prime} 35^{\prime \prime}$. Limita-se a Norte com o Oceano Atlântico, ao Sul com as cidades de Pacatuba, Eusébio, Maracanaú e Itaitinga, a Leste com a cidade de Aquiraz e o Oceano Atlântico e a Oeste com o município de Caucaia. O município de Fortaleza conta com $25 \mathrm{~km}$ de orla em seu território (BRASIL, 2015). A Figura 1 apresenta o mapa da área deste estudo inserida no município de Caucaia, região metropolitana de Fortaleza /CE.

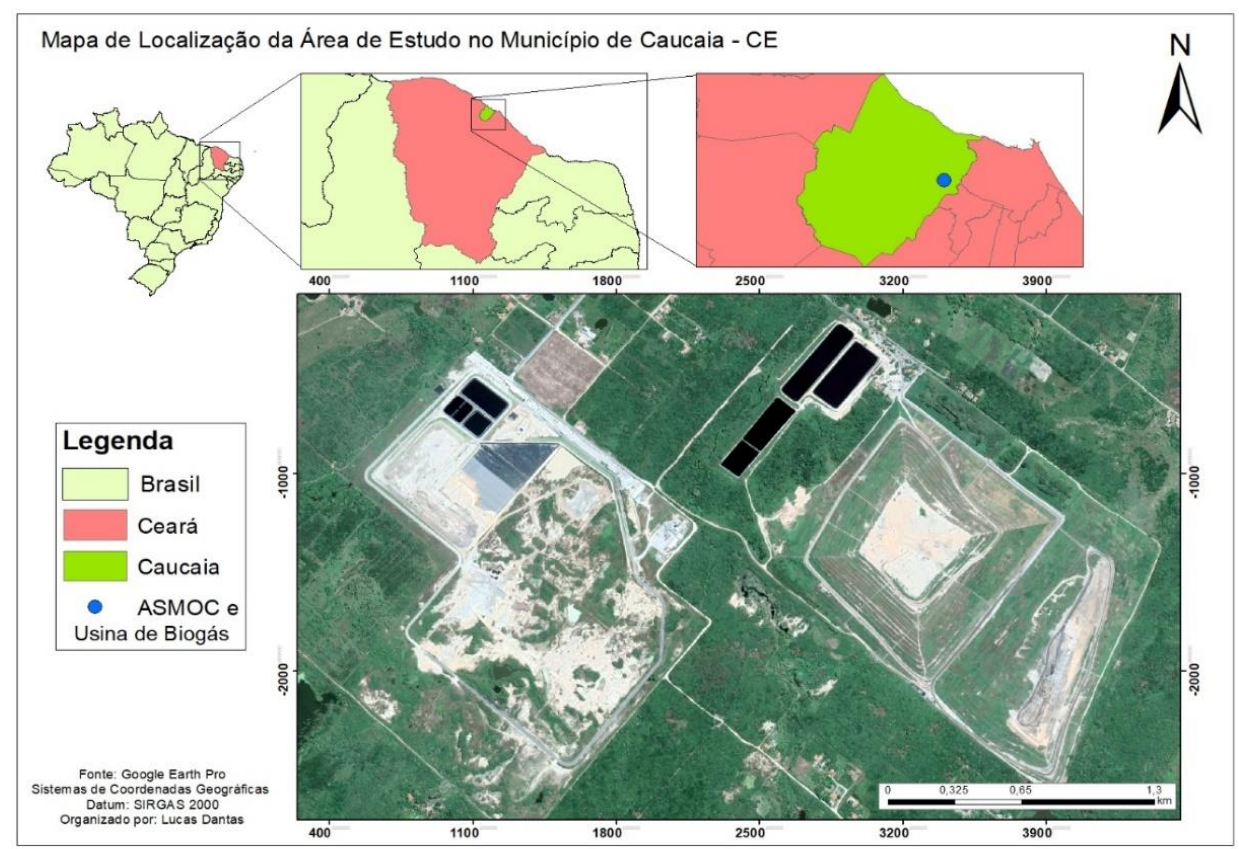

Figura 1: Aterro sanitário ASMOC e a Usina de biogás GNR Fortaleza CE- Localizados no município de Caucaia no Estado do Ceará.

Elaboração: Lucas Dantas, 2020

O Aterro Sanitário Metropolitano Oeste de Caucaia (ASMOC) está localizado no município de Caucaia, a leste do loteamento Jardim Fortaleza, e equivale a uma área de 123 ha. O acesso é feito pela Rodovia Federal BR- 020 na altura do $\mathrm{Km} 15$ por um percurso de 1,6Km em asfalto, construído a partir da margem sul da referida rodovia. O ASMOC foi inaugurado no ano de 1998, com objetivo de receber o lixo produzido pelo polo metropolitano, substituindo 
os mais de 1.800 "pontos de lixo"5 e o lixão do Jangurussu (Fortaleza), desativado pelo Governo do Estado do Ceará (CARVALHO, 2016).

A operacionalização do ASMOC é realizada pela Ecofor Ambiental S/A do Grupo Marquise. As empresas Autarquia de Regulação, Fiscalização e Controle dos Serviços Públicos de Saneamento Ambiental - ACFOR e a Empresa Municipal de Limpeza e Urbanização - EMLURB são responsáveis pela vistoria do Grupo Marquise (PMGIRS, 2012; CARVALHO, 2016).

O lixo recebido no aterro sanitário do $A S M O C$ é proveniente dos municípios de Fortaleza e Caucaia e compreende os resíduos sólidos oriundos da coleta domiciliar, comercial, varrição, capinação, serviços de saúde, dentre outros. O ASMOC é localizado no município de Caucaia, tendo em vista, o município de Fortaleza não contar com terreno disponível para esse fim. A falta de coleta seletiva reduziu em 4 anos a vida útil de 20 anos do ASMOC (PMGIRS, 2012).

Com o encerramento da vida útil do ASMOC, no ano de 2014, foi realizada a compra de um terreno com 23 hectares ao lado do ASMOC e instalou-se o novo aterro sanitário. Nesse novo aterro sanitário instalou-se a usina de biogás GNR Fortaleza com o objetivo de captar os gases gerados no ASMOC e produzir biogás ou biometano a partir do lixo. A seguir na figura 2 são identificadas a área do novo aterro sanitário ASMOC, a usina GNR e seu entorno (PMGIRS,2012; SEMACE, 2019).

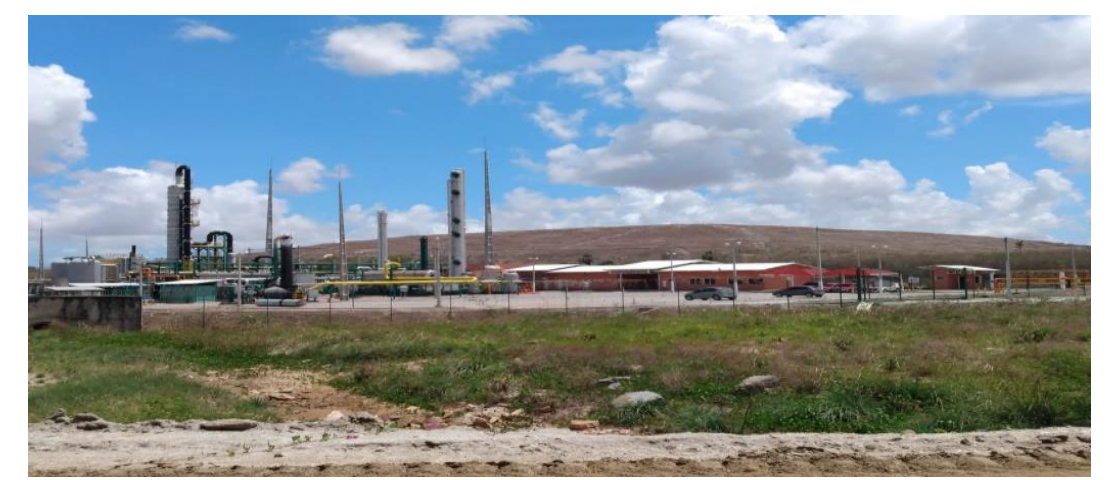

Figura 2: Localização do novo aterro sanitário do ASMOC e da usina de biogás GNR Fortaleza. Foto: Autoria própria, 2020.

A Figura 2 apresenta o novo aterro sanitário do ASMOC e a usina de biogás GNR Fortaleza, em Caucaia, Ceará. A criação desse novo aterro ocorreu, tendo em vista o encerramento da vida útil do aterro sanitário ASMOC que há mais de 20 anos recebeu o lixo das cidades de Fortaleza e Caucaia/CE.

\footnotetext{
5 "Ponto de lixo" são resíduos sólidos dispostos de maneira irregular em vários pontos da cidade de Fortaleza. A estimativa de composição de resíduos de "pontos de lixo" é de entulhos (resíduos de construção e demolição e resíduos volumosos), com $56 \%$, seguidos por resíduos domiciliares (28\%) e podação (16\%) (PMGIRS, 2012).
} 


\section{Procedimentos Metodológicos}

Para a realização da pesquisa, inicialmente foi realizado um levantamento bibliográfico e documental da temática e área de estudo. Posteriormente, foi realizado o reconhecimento da área de estudo através de visita de campo e registro fotográfico. Foram realizadas entrevistas e aplicados questionários temáticos semiestruturados com os atores sociais presentes na usina e no aterro sanitário visando uma melhor compreensão da problemática em questão. $O$ aporte teórico para a análise de interpretação dos dados se baseou nas concepções de: Esmaeilian et al. (2018), Centrulo et. al. (2020), Guerrero, Maas e Hogland (2013), Castro e Mateus(2016), Souza et. al. (2019), Sánchez(2008), Magalhães(1986), Muylaert (2000), dentre outros.

Para a identificação e classificação dos impactos ambientais na área de estudo, foram consultados os seguintes documentos: Licença Prévia (LP), Licença de Instalação (LI),Licença de Operação (LO), Plano de Gerenciamento de Resíduos Sólidos - PGRS, Descritivo Produtivo da GNR (DPG/2017), Estudo de Consequências e Vulnerabilidade (ECV), Relatório de Avaliação de Risco (RAR-295/2014),Plano de Atendimento a Emergência (PAE/2017), Análise Preliminar de Perigo (APP),Estudo de Impacto Ambiental EIA e respectivo Relatório de Impacto Ambiental - RIMA, dentre outros documentos. Os documentos supracitados disponibilizados pela Superintendência Estadual do Meio Ambiente (2019) serviram de base para identificar in loco os impactos ambientais e classificá-los em positivos e lou negativos provenientes da instalação e operacionalização do ASMOC e da Usina de Biogás na área de estudo.

\section{Resultados e discussão}

Os resultados dessa discussão em estudo sinalizaram que existe impactos ambientais positivos e negativos com a instalação e operacionalização do aterro sanitário e da usina de biogás GNR Fortaleza. Tais impactos estão situados num contexto de RSU que necessita de Educação Ambiental. Essa educação é compreendida na acepção de Zanetti (2003) como uma práxis voltada para a cidadania e transformação social.

Para Esmaeilian et al. (2018) e Centrulo et al. (2020), o aumento da população brasileira, consequentemente tem-se um grande potencial de geração de resíduos sólidos. O que para Burnley (2007) e Guerrero et al. (2013) sinalizaram que com o aumento da população e dos resíduos sólidos tem- se aumento da problemática socioambiental e econômica se não existirem ações de educação socioambiental a exemplo da coleta seletiva implantada no município. Dessa forma, as Tabelas 1 e 2 a seguir apresentam como se deu o aumento da geração dos resíduos sólidos para o aterro ASMOC e o aumento da população durante o período de 6 anos, de 2014 a 2019. Situações essas que levaram à necessidade de se instalar a usina de biogás GNR. 
Tabela 1: Demonstrativo da produção geral de Resíduos Sólidos Domiciliares (RSD) gerados em toneladas ano, no município de Fortaleza, dos anos de 2014 a 2019.

\begin{tabular}{|c|c|c|}
\hline ANO & $\begin{array}{c}\text { QUANTIDADE } \\
\text { (Ton/ano) }\end{array}$ & $\begin{array}{c}\text { MÉDIA } \\
\text { (Ton/mês) }\end{array}$ \\
\hline 2014 & $595.725,81$ & $49.643,81$ \\
\hline 2015 & $606.962,53$ & $50.580,21$ \\
\hline 2016 & $588.213,68$ & $49.017,81$ \\
\hline 2017 & $597.505,82$ & $49.792,15$ \\
\hline 2018 & $625.217,09$ & $52.101,42$ \\
\hline 2019 & $635.510,05$ & $52.959,17$ \\
\hline $\begin{array}{c}\text { Total de Resíduos Sólidos Domiciliares Depositados no aterro } \\
\text { ASMOC de 2014 até 2019 }\end{array}$ & $3.649 .134,98$ Ton & $304.094,57$ \\
\hline
\end{tabular}

Fonte: Baseada em dados da Secretaria Municipal de Conservação e Serviços Públicos

(SMCSP, 2019).

De acordo com os dados fornecidos pela Secretaria Municipal de Conservação e Serviço Público (SMCSP) apresentados na Tabela 1, no período de 6 anos, a média de produção de RSU descartados no aterro do ASMOC, cresceu em $6,66 \%$, enquanto a população cresceu em $3,73 \%$, por igual período, conforme apresentado na Tabela 2 (SMCSP, 2019; IBGE,2020).

Tabela 2 - População do município de Fortaleza no período de 2014 a 2019.

\begin{tabular}{|l|l|}
\hline \multicolumn{1}{|c|}{ ANO } & POPULAÇÃO \\
\hline 2014 & 2.571 .896 \\
\hline 2015 & 2.591 .188 \\
\hline 2016 & 2.609 .716 \\
\hline 2017 & 2.627 .482 \\
\hline 2018 & 2.643 .000 \\
\hline 2019 & 2.669 .342 \\
\hline
\end{tabular}

Fonte: Baseada em dados do IBGE, 2019.

Diante do exposto nas Tabelas 1 e 2, tendo em vista o aumento populacional e a crescente geração dos resíduos sólidos faz -se necessário ações de Educação Ambiental a exemplo da coleta seletiva, compostagem e reciclagem a serem implantadas pelo município, sob pena de aumentar a problemática ambiental, econômica e social e não cumprir com a Resolução CONAMA no 404/2008, que dispõe em seu capitulo XV sobre programa de educação e coleta seletiva (BURNLEY, 2007;CONAMA,2008;GUERRERO et. al., 2013; ESMAEILIAN et al., 2018; CENTRULO et al., 2020). A reciclagem reduz impactos ambientais (GONÇALVES et al.,2019). As Figuras 3 e 4 a seguir sinalizam a insuficiência na gestão dos resíduos sólidos. 


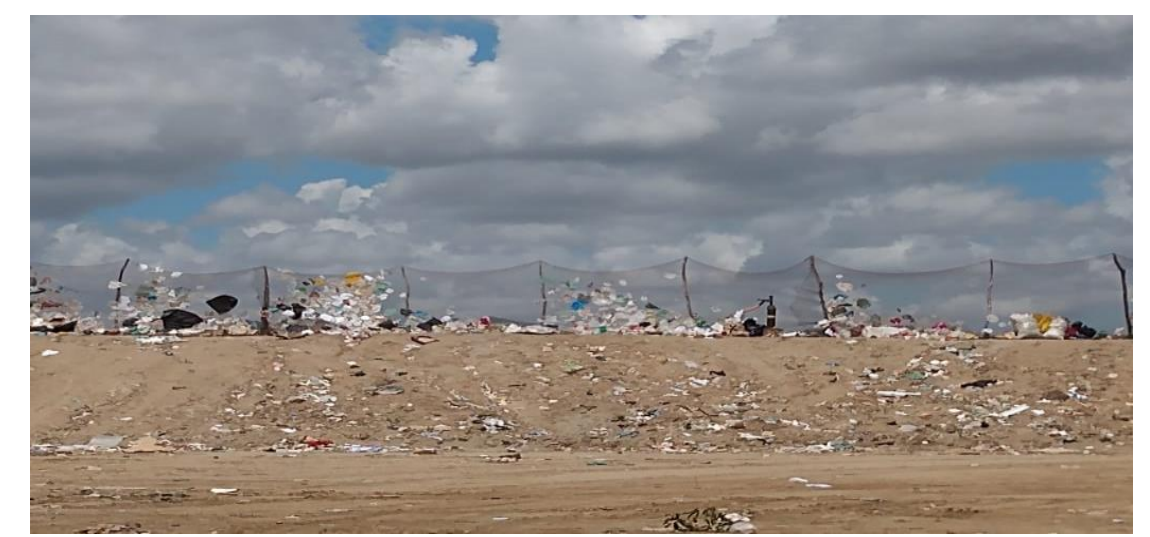

Figura 3: Tela de proteção de resíduos sólidos no aterro sanitário ASMOC.

Foto: Autoria própria, 2020.

Mesmo com a tela de proteção para conter a grande quantidade de resíduos sólidos nos taludes do ASMOC, essa medida de contenção é insuficiente, tendo em vista a ação do vento levar os resíduos para todas as direções o que acaba ocorrendo aumento da poluição e da contaminação do solo e corpos hídricos do entorno imediato.

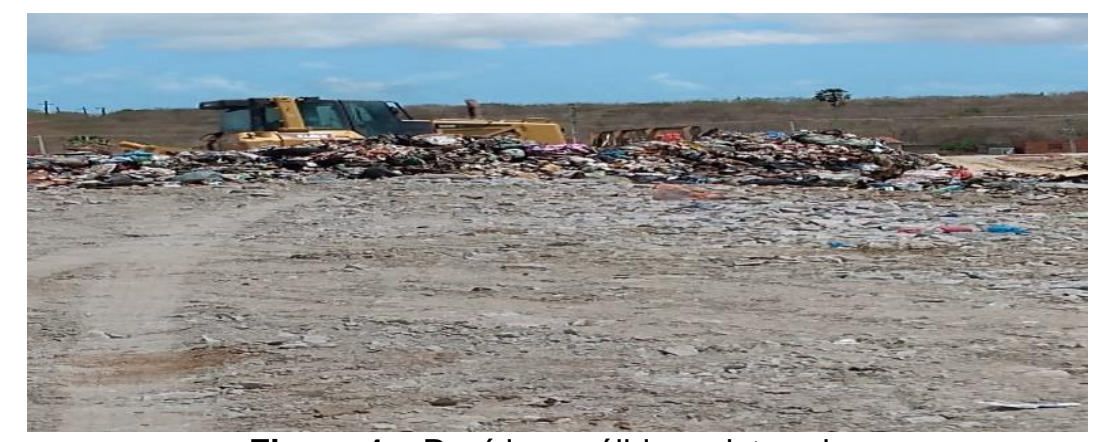

Figura 4 - Resíduos sólidos misturados

Foto: Autoria própria, 2020.

A Figura 4 apresenta uma enorme quantidade de resíduos sólidos que poderia ser reciclada como latas, sacolas plásticas, papel, dentre outros.

A taxa da geração per capita (TGP) no ano de 2019, com um índice de $2,02 \mathrm{~kg} / \mathrm{hab} / \mathrm{dia}$, é outro elemento da política de gestão dos resíduos sólidos que exige reflexão nesse município, tendo em vista a média nacional ser de $1,04 \mathrm{~kg} / \mathrm{hab} / \mathrm{dia}$. Esse indicador diz respeito ao poder aquisitivo e 0 grau de urbanização dos municípios (ABRELPE, 2017).

Os resíduos sólidos são coletados sem sua devida separação e sem a devida composição, o que demanda em desperdício de dinheiro e deixa de gerar emprego e renda, como mostra a Tabela 3 a seguir (CARVALHO, 2016; CICLOVIVO, 2018). 
Tabela 3: Estimativa de ganho com a reciclagem no município de Fortaleza/CE

\begin{tabular}{|c|c|}
\hline População de Fortaleza - Ceará & 2.669.342(IBGE, 2019) \\
\hline Produção Per capta & $\begin{array}{l}\text { 1,98. kg/hab/lixo }(5.295 .000 / 2.669,342=1,8 \\
\mathrm{kg} / \mathrm{hab} / \mathrm{lixo} / \mathrm{dia})\end{array}$ \\
\hline $\begin{array}{l}\text { Produção diária de resíduos sólidos } \\
\text { domiciliar }\end{array}$ & $5.295 .000 \mathrm{~kg} / \mathrm{dia}(5.295 \mathrm{ton} / \mathrm{dia})(\mathrm{SMCSP}, 2019)$ \\
\hline Produção de reciclado/dia & $\begin{array}{l}30,0 \% \text { dia }(\mathrm{SMCSP}, 2019)-1.588 .500 \mathrm{Kg} / \\
\text { ton/dia }\end{array}$ \\
\hline Estimativa de renda/dia & $1.588 .500 \mathrm{Kg} / \mathrm{dia} \times(\mathrm{R} \$ 0,5 \mathrm{Kg})=\mathrm{R} \$ 794.250 / \mathrm{dia}$ \\
\hline Produção de Reciclado/ mês & $\begin{array}{l}794.250 \mathrm{~kg} / \mathrm{mês} \text { X } 30 \text { dias } \\
23.827 .500 \mathrm{~kg} / \mathrm{mês}\end{array}$ \\
\hline Estimativa de renda/mês & $\mathrm{R} \$ 23.827 .500 /$ mês \\
\hline
\end{tabular}

Fonte: Baseada em dados da SMCSP,2019

Diante do observado, o município de Fortaleza/Ceará deixa de arrecadar o montante de $\mathrm{R} \$ 23.827 .500$ (vinte e três milhões, oitocentos e vinte e sete mil e quinhentos) mês com a reciclagem pela insuficiência da gestão municipal no aprimoramento de toda cadeia produtiva dos resíduos sólidos. Esse quadro é diferente do que ocorre na União Europeia, que tem 42,2\% de aproveitamento dos seus resíduos sólidos urbanos, ou seja, são "gerenciados através de aterros sanitários $(33,6 \%)$, incineração $(24,2 \%)$, reciclagem $(27,4 \%)$ e compostagem e digestão anaeróbica (14,8\%)" (COLAZO et al., 2015; BRAGAGNOLO et al., 2020,p.955).

Outro impacto negativo observado na área de estudo, é o fato do biometano canalizado gerado na usina GNR não chegar às cozinhas da população do entorno. O gás natural gerado pela usina beneficia apenas a população fora do entorno do aterro sanitário, ou seja, a mais rica.

A usina de biogás GNR Fortaleza no Ceará, assim como outras usinas a exemplo da usina Asja no município de Jaboatão dos Guararapes no Estado do Pernambuco, a usina Central Termelétrica Biogás no aterro dos Bandeirantes em São Paulo, as usinas da cidade do Rio de Janeiro, como a Refinaria Duque de Caxias (REDUC) e a Usina de Tratamento de Biogás Dois Arcos, impactam negativamente o ambiente ao receberem os resíduos sólidos sem a separação ambientalmente adequada, assim como a população do entorno não ser beneficiada com a energia elétrica ou biometano por essas produzidos. Embora, as usinas citadas impactem positivamente quando realizam 0 aproveitamento do biogás e com isso mitigam a emissão dos gases de efeito estufa (GEE) e reduzem o uso de energia não renovável.

A Tabela 4 a seguir, apresenta os impactos ambientais gerados com a instalação e operacionalização da usina de biogás advindos de resíduos sólidos do aterro sanitário ASMOC: 
Tabela 4: Impactos ambientais nas fases de operação da Usina GNR Fortaleza.

\begin{tabular}{|c|c|c|c|}
\hline $\begin{array}{c}\text { Fases de Operacionaliza- } \\
\text { ção - Usina de Biogás } \\
\text { GNR Fortaleza }\end{array}$ & Descrição das Fases & $\begin{array}{c}\text { Meio } \\
\text { socioambiental }\end{array}$ & Impactos Ambientais \\
\hline $\begin{array}{l}\text { FASE 1: } \\
\quad \text { Sistema de Captação }\end{array}$ & $\begin{array}{l}\text { A coleta de gás começa nos } \\
\text { poços de extração, onde o } \\
\text { biogás é extraído da massa } \\
\text { de resíduos. A extração dos } \\
\text { poços é tipicamente } \\
\text { composta de tubos de } \\
\text { PEAD com furos, rodeado } \\
\text { por pedra ou outro material } \\
\text { granulado e manilha para } \\
\text { proteção mecânica dos } \\
\text { poços. Acima da superfície } \\
\text { da massa de resíduos, } \\
\text { localiza-se o cabeçote de } \\
\text { extração que possui uma } \\
\text { válvula para permitir a } \\
\text { regulação de vácuo e de } \\
\text { amostragem do biogás. A } \\
\text { orientação desses poços } \\
\text { pode ser vertical ou } \\
\text { horizontal. }\end{array}$ & $\begin{array}{l}\text { Meio físico: ar } \\
\text { e solo - } \\
\text { Positivo/ } \\
\text { negativo } \\
\text { Meio biótico: } \\
\text { fauna e flora } \\
\text { - Negativo } \\
\text { Meio } \\
\text { antrópico: } \\
\text { geração de } \\
\text { emprego } \\
\text { - Positivo }\end{array}$ & $\begin{array}{l}\text { Vias não pavimentadas } \\
\text { - A gestão não viabilizar } \\
\text { vias pavimentadas para a } \\
\text { circulação dos moradores } \\
\text { do entorno. } \\
\text { (negativo). } \\
\text { Ocupação de grande } \\
\text { área do solo para a } \\
\text { instalação(negativo). } \\
\text { Modificação da } \\
\text { paisagem natural com } \\
\text { alteração da flora e } \\
\text { fauna(negativo). } \\
\text { Mitigação dos gases de } \\
\text { efeito estufa (positivo). }\end{array}$ \\
\hline $\begin{array}{l}\text { FASE 2: } \\
\text { Sistema de purificação } \\
\text { produção }\end{array}$ & $\begin{array}{l}\text { O gás é encaminhado para } \\
\text { a seção de purificação cujo } \\
\text { objetivo principal é a } \\
\text { remoção de } \mathrm{CO}_{2} \text {, Siloxanos } \\
\text { e compostos orgânicos } \\
\text { voláteis. A purificação do } \\
\text { biogás para conversão em } \\
\text { biometano é feita em duas } \\
\text { etapas: A Primeira etapa } \\
\text { consiste no pré tratamento, } \\
\text { remover VOC (Compostos } \\
\text { Orgânicos Voláteis), HCs } \\
\text { (hidrocarbonetos pesados), } \\
\text { siloxanos e água da } \\
\text { corrente de biogás. A } \\
\text { Segunda etapa é a } \\
\text { Purificação propriamente } \\
\text { dita onde há a remoção do } \\
\text { CO} \text { do biogás de forma a } \\
\text { atingir as especificações } \\
\text { definidas pela legislação. O } \\
\text { produto do sistema de } \\
\text { purificação é o Biometano. }\end{array}$ & $\begin{array}{l}\text { Meio físico: ar } \\
\text { e solo - } \\
\text { Positivo/ } \\
\text { negativo } \\
\text { Meio biótico: } \\
\text { fauna e flora } \\
\text { - Negativo } \\
\text { Meio } \\
\text { antrópico: } \\
\text { geração de } \\
\text { emprego } \\
\text { - Positivo }\end{array}$ & $\begin{array}{l}\text { Presença de ruído } \\
\text { (negativo) } \\
\text { - Produção de biometano } \\
\text { - gás natural renovável e } \\
\text { limpo (positivo). }\end{array}$ \\
\hline
\end{tabular}

Continua...

Revbea, São Paulo, V. 16, № 4: 227-247, 2021. 
...continuação.

\begin{tabular}{|c|c|c|c|}
\hline $\begin{array}{c}\text { Fases de Operacionaliza- } \\
\text { ção - Usina de Biogás } \\
\text { GNR Fortaleza }\end{array}$ & Descrição das Fases & $\begin{array}{c}\text { Meio } \\
\text { socioambiental }\end{array}$ & $\begin{array}{l}\text { Impactos } \\
\text { Ambientais }\end{array}$ \\
\hline 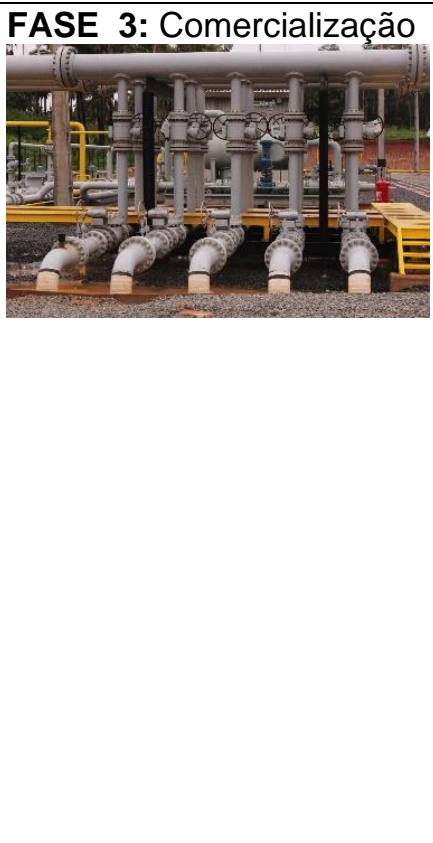 & $\begin{array}{l}\text { A Usina GNR FORTALEZA } \\
\text { tem como objetivo captar, } \\
\text { purificar e distribuir o biogás } \\
\text { gerado no aterro sanitário } \\
\text { ASMOC, transformando-o em } \\
\text { Biometano que pode ser } \\
\text { aproveitado como } \\
\text { combustível em substituição } \\
\text { ao gás natural de origem } \\
\text { fóssil. O processo } \\
\text { compreende uma rede de } \\
\text { coleta do biogás, uma planta } \\
\text { de purificação e compressão } \\
\text { que está localizada nas } \\
\text { imediações do atual aterro, } \\
\text { ocupando uma área } \\
\text { aproximada de } 15.000 \text { m². O } \\
\text { Biometano será injetado no } \\
\text { gasoduto da CEGÁS para } \\
\text { distribuição até o consumidor } \\
\text { final. }\end{array}$ & $\begin{array}{l}\text { Meio físico: ar } \\
\text { e solo - } \\
\text { Positivo/ } \\
\text { negativo } \\
\text { Meio biótico: } \\
\text { fauna e flora } \\
\text { - Negativo } \\
\text { Meio antrópico: } \\
\text { geração de } \\
\text { emprego e } \\
\text { renda } \\
\text { - Positivo } \\
\text { - Negativo }\end{array}$ & $\begin{array}{l}\text { Comercializar } \\
\text { biometano para } \\
\text { comércio, } \\
\text { residências e } \\
\text { indústrias } \\
\text { (positivo). } \\
\\
\text { _Proporcionar } \\
\text { crescimento e } \\
\text { desenvolvimento } \\
\text { econômico e } \\
\text { sustentabilidade } \\
\text { socioambiental(po } \\
\text { sitivo). } \\
\text { A população do } \\
\text { entorno não ser } \\
\text { beneficiada com o } \\
\text { biometano gerado } \\
\text { na } \\
\text { usina(negativo). }\end{array}$ \\
\hline
\end{tabular}

Fonte/Foto: Adaptada de Matriz de Leopold, 1971; Semace, 2019; Cegás, Usina GNR Fortaleza, 2020; Autoria própria ,2020.

Ao analisar as fases de instalação e operacionalização da usina de biogás GNR Fortaleza percebeu-se que a fase de captação traz impactos positivos e negativos nos meios físico, biótico e antrópico. No meio físico, a emissão de gases com liberação de material inflamável e tóxico deixa o ar poluído e com mal cheiro tendo em vista a decomposição dos resíduos sólidos e o chorume nas lagoas anaeróbias. O solo é impactado com o tráfego intenso de caminhões para o transporte dos resíduos sólidos, e a maioria das vias do entorno não são pavimentadas. Com isso, no período chuvoso tornam intransitáveis devido aos pontos de alagamentos. O meio biótico apresenta impactos negativos, tendo em vista, a derrubada de plantas nativas para a instalação do aterro sanitário. Outros impactos negativos observados in loco dizem respeito a desapropriação das famílias do entorno que perderam seus laços afetivos de seu lugar de origem. Além disso, a desvalorização imobiliária é outro fator que afeta os moradores do entorno. Como impacto positivo, destaca-se o descarte dos resíduos sólidos urbano dentro das normas ambientais e aproveitamento desse material para a produção de biogás.

No que se refere à fase de purificação/produção do biogás também apresenta impactos positivos e negativos. Como impacto positivo de grande relevância no meio físico é o fato da usina de biogás retirar do ar grande parte das emissões de gases de efeito estufa a exemplo do metano $\left(\mathrm{CH}_{4}\right)$ e Dióxido de carbono (CO2) e produzir energia limpa, renovável e sustentável por meio do biometano. Como impacto negativo destaca-se o ruído durante a geração 
do biometano, de forma que é obrigatório o ouso de protetor auricular por parte de funcionários e visitantes. No meio antrópico destaca-se como impacto positivo de relevância a geração de emprego e renda. No entanto, vale destacar a insuficiência na quantidade de geração de emprego por parte dos que moram no entorno se comparado aos benefícios que os proprietários dos empreendimentos obtêm.

$\mathrm{Na}$ fase de comercialização também existem impactos positivos e negativos que ocorrem na área de estudo. Como impacto positivo, destaca - se o uso de combustível renovável e limpo em indústrias, residências e comércios por um preço barato se comparado ao combustível fóssil. No que diz respeito aos impactos negativos nessa fase de operação percebe-se que a população do entorno não é beneficiada com o uso do biometano que é comercializado fora do contexto dos moradores locais. Quem tem acesso são as famílias mais ricas.

De acordo com a intensidade do impacto ambiental, o órgão ambiental solicita um tipo de Estudo Ambiental específico. Para a usina de biogás GNR a Semace solicitou o Plano de Atendimento a Emergência (PAE) elaborado pelos técnicos da usina de biogás GNR, assim como o Relatório de Análises de Riscos. Ainda foi solicitado pela Semace a elaboração de um Plano de Gerenciamento de Resíduos Sólidos (PGRS), para a identificação dos resíduos e a destinação a ser dada aos mesmos, assim como um Descritivo Produtivo da GNR (DPG), também, o Estudo de Consequências e Vulnerabilidade (ECV), ainda, o Relatório de Avaliação de Risco (RAR-295), o Plano de Atendimento a Emergência (PAE) e a Análise Preliminar de Perigo (APP). Dessa forma, de acordo com a Superintendência Estadual do Meio Ambiente (Semace) do Estado do Ceará, órgão responsável para analisar, avaliar e dar autorização para a instalação e operacionalização a usina GNR atendeu a todas as exigências pelo referido órgão (BURTON et al., 1978; SEMACE, 2019).

\section{Potencialidades provenientes da instalação da Usina de Biogás GNR Fortaleza}

De acordo com documentos analisados pela Semace e segundo Thales Motta Junior, gerente da usina GNR, desde o ano de 2017 a usina de biogás GNR Fortaleza produz combustível para abastecer indústrias, residências, comércios e veículos. Ainda, desde a implantação aos dias atuais gerou 28 empregos diretos e 30 indiretos, contando com 2 funcionários do sexo feminino e 26 do sexo masculino para sua operacionalização geral (informação verbal) ${ }^{6}$. $\mathrm{O}$ quantitativo de funcionários também se confirma no quadro funcional da empresa. No que diz respeito à segurança do trabalho, de acordo com visitas em campo foi observado que é disponibilizado EPI para os funcionários, a exemplo de máscaras de gases, capacete, óculos de segurança, vestimentas,

${ }^{6}$ Informação coletada em entrevista a Thales Motta Júnior, em novembro de 2020. 
protetores auriculares, dentre outros. A jornada de trabalho compreende $12 \times 36 \mathrm{~h}$ para os que trabalham na planta de purificação de biogás. Já para os operadores de captação e setor administrativo são 44h semanais de segunda a sexta 7:30h às $17 \mathrm{~h}$ e aos sábados de $07 \mathrm{~h}$ às $11 \mathrm{~h}$. Com relação a formação ou qualificação e/ou treinamento para seus colaboradores, a empresa realiza semestralmente cursos de capacitação.

Para Alessandro Gardemann, presidente da Associação Brasileira de Biogás (ABiogás), o biometano produzido na planta da GNR - Fortaleza, reduz em $96 \%$ as emissões de CO2 em comparação com o diesel e o Ceará tem o potencial de gerar cerca de 1,1 bilhão de metros cúbicos por ano ( $\left.\mathrm{m}^{3} / \mathrm{ano}\right)$ de biogás(DIÁRIO DO NORDESTE, 2019).

A Tabela 5 a seguir apresenta as usinas de biogás que mais se destacam no território brasileiro na geração combustível renovável para indústrias, residências, veículos, comércios e energia elétrica renovável. Dentre elas, destaca a GNR Fortaleza.

Tabela 5: Principais usinas de aproveitamento do biogás para geração de biometano a partir de resíduos sólidos urbanos de aterro sanitário implantadas no Brasil.

\begin{tabular}{|c|c|c|c|c|c|}
\hline Usina de Biogás & $\begin{array}{c}\text { Potencia máxima } \\
\mathrm{MW} / \mathrm{m}^{3}\end{array}$ & Município & UF & $\begin{array}{c}\text { Ano de } \\
\text { Fundação }\end{array}$ & $\begin{array}{l}\text { Aterro Sanitário } \\
\text { (AT) }\end{array}$ \\
\hline $\begin{array}{l}\text { Usina de Gás } \\
\text { Verde Gramacho }\end{array}$ & $\begin{array}{c}49 \mathrm{mil} \mathrm{m}^{3} \\
\text { biometano /dia }\end{array}$ & $\begin{array}{l}\text { Duque de } \\
\text { Caxias }\end{array}$ & RJ & 2014 & AT de Gramacho \\
\hline $\begin{array}{c}\text { Usina de } \\
\text { Tratamento de } \\
\text { Biogás Dois Arcos }\end{array}$ & $\begin{array}{c}15 \mathrm{mil} \mathrm{m}^{3} \\
\text { biometano /dia }\end{array}$ & $\begin{array}{l}\text { São Pedro } \\
\text { da Aldeia }\end{array}$ & RJ & 2014 & AT Dois Arcos \\
\hline $\begin{array}{c}\text { Usina Nova Iguaçu } \\
\text { Energia e Gás } \\
\text { Renovável }\end{array}$ & 18 & $\begin{array}{l}\text { Nova Iguaçu } \\
\text { na Baixada } \\
\text { Fluminense }\end{array}$ & RJ & 2019 & $\begin{array}{l}\text { AT Central de } \\
\text { Tratamento de } \\
\text { Resíduos de } \\
\text { Nova Iguaçu }\end{array}$ \\
\hline $\begin{array}{l}\text { Usina Siderúrgica } \\
\text { Ternium Brasil }\end{array}$ & 8,5 & Seropédica & RJ & 2019 & AT da Seropédica \\
\hline $\begin{array}{c}\text { Usina Central } \\
\text { Termelétrica } \\
\text { Biogás de } 20 \mathrm{MW}\end{array}$ & 22,2 & São Paulo & SP & 2004 & $\begin{array}{c}\text { AT dos } \\
\text { Bandeirantes }\end{array}$ \\
\hline $\begin{array}{c}\text { Usina Termelétrica } \\
\text { São João Energia } \\
\text { Ambiental S. A }\end{array}$ & 22,4 & $\begin{array}{l}\text { Sítio São } \\
\text { João }\end{array}$ & SP & 2008 & AT São João \\
\hline $\begin{array}{l}\text { Usina de Biogás } \\
\text { de Guatapará }\end{array}$ & 4,2 & Guatapará & SP & 2014 & AT de Guatapará \\
\hline Usina ZEG Biogás & & São Mateus & SP & 2019 & $\begin{array}{l}\text { AT Centro de } \\
\text { Tratamento de } \\
\text { Resíduos Leste }\end{array}$ \\
\hline $\begin{array}{c}\text { Usina Asja Per- } \\
\text { nambuco Serviços } \\
\text { Ambientais LTDA }\end{array}$ & 11,4 & $\begin{array}{c}\text { Jaboatão dos } \\
\text { Guararapes }\end{array}$ & PE & 2018 & AT da Muribeca \\
\hline $\begin{array}{l}\text { Usina de biometa- } \\
\text { no Gás Natural } \\
\text { Renovável - GNR } \\
\text { Fortaleza Valoriza- } \\
\text { ção de Biogás tda. }\end{array}$ & $\begin{array}{c}80 \mathrm{mil} \mathrm{m}^{3} \\
\text { biometano /dia }\end{array}$ & Caucaia & CE & 2018 & $\begin{array}{l}\text { AT Metropolitano } \\
\text { Oeste de Caucaia }\end{array}$ \\
\hline
\end{tabular}

Fonte: EXAME, PETROBRAS,2014; CETESB, 2017; ABRELPE, 2015; CICLOVIVO, 2019. 
Vale destacar, que o município de Fortaleza /CE cumpre a Lei 12.305 do ano 2010 da Política Nacional dos Resíduos Sólidos no que se refere a existência do aterro sanitário para a disposição final dos resíduos sólidos domiciliares e urbanos, assim como o aproveitamento do gás na geração do biometano de forma a mitigar as emissões de metano e gás carbônico que provocam o efeito estufa (BRASIL, 2010).

No Estado do Ceará, a produção de GNR atende cerca de $30 \%$ da demanda para o uso de gás natural renovável. A transformação do metano $\left(\mathrm{CH}_{4}\right)$ em biometano, evita o uso do Gás Liquefeito de Petróleo (GLP), ou gás de cozinha, que é um combustível fóssil, ou seja, uma energia não renovável, muito mais cara que o gás de cozinha da GNR advindo do aterro sanitário. Essa produção, também evita a importação de gás natural. Assim sendo, a usina GNR-Fortaleza cumpre com o inciso V do Art. 15 da Política Nacional dos Resíduos Sólidos (PNRS/2010), no que se refere às metas para o aproveitamento energético dos gases gerados em aterro sanitário, embora o acesso poderia ser para todos, inclusive à população do entorno (CICLOVIVO, 2018).

Nesse contexto, a usina de biogás, pelo fato de mitigar as emissões de gases de efeito estufa, pode estar colaborando para diminuir a radiação de raios UV-B. Segundo a Companhia Ambiental do Estado de São Paulo (CETESB) o Programa Estadual de Prevenção à Destruição da Camada de Ozônio (PROZONESP), dados divulgados pelo Instituto Nacional de Câncer (INCA), afirma que o câncer de pele representa $30 \%$ dos tumores malignos diagnosticados no Brasil. Isto se deve em decorrência da destruição da camada de ozônio, onde os raios UV-B com a radiação estão diretamente relacionados ao aparecimento do câncer de pele(CETESB, 2018).

Outro impacto positivo observado pelo uso do biometano, é que o Gás Natural Renovável (GNR) é mais barato do que o Gás Liquefeito de Petróleo (GLP), diante a realidade no mercado. O gás da GNR Fortaleza é usado em diversos condomínios no município de Fortaleza /CE.

No município de Fortaleza, o custo do botijão de $13 \mathrm{Kg}$ do Gás Liquefeito de Petróleo (GLP), é de 80 reais, ou seja, cada quilo do GLP custa $R \$ 6,16$ (Seis reais e dezesseis centavos). Com os dados desta pesquisa junto à usina GNR e dos condomínios que fazem uso do gás natural renovável, constatou-se que o GNR custa apenas $R \$ 3,18$ (três reais e dezoito centavos). Portanto, uma diferença em cada quilo de $R \$ 2,98$ (Dois reais e noventa e oito centavos), ou seja, o GNR é $52 \%$ mais barato do que o GLP. A Tabela 6 a seguir, mostra a média de preço do GNR (JORNAL O POVO, 2019). 
Portanto, sabe - se que tanto o aterro sanitário ASMOC, quanto a usina de biogás GNR Fortaleza são empreendimentos de grande relevância para o meio ambiente quando da mitigação dos gases de efeito estufa, assim como, da geração do biometano combustível renovável que substituirá os combustíveis fósseis usados em indústrias, residências, comércios e veículos automotores. Ainda, tornando o preço dos referidos combustíveis mais acessíveis. E, dessa forma, proporcionando o meio ambiente cada vez mais sustentável. O modelo de geração de biogás da usina GNR sinaliza que pode ser replicado nos municípios brasileiros. No entanto, cabe a esses atores de gestão dos resíduos sólidos urbanos proporem ações de Educação Ambiental direcionadas à transformação social, com geração de emprego e renda.

Portanto, a partir deste estudo, propõe- se à gestão dos resíduos sólidos urbanos dos municípios de Fortaleza e Caucaia no Estado Ceará, adotarem de forma contínua, a institucionalização da coleta seletiva nos mais de 119 bairros da cidade, implantar as ações da política dos 3 Rs: reciclar, reutilizar e reduzir os resíduos sólidos urbanos e se adequar ao TGP nacional.

\section{Referências}

ABRELPE. Associação Brasileira de Empresas de Limpeza Pública e Resíduos Especiais. Estimativa dos custos para viabilizar a universalização da destinação adequada de resíduos sólidos no Brasil. Disponível em 07 set 2018, em: <http://abrelpe.org.br/mativa-dos-custos-para-viabilizar-a-universali zacao-da-destinacao-adequada-de-residuos-solidos-no-brasil/>. Acesso em 14 mar 2020.

ABRELPE. Associação Brasileira de Empresas de Limpeza Pública e Resíduos e Resíduos Especiais. Caderno informativo de recuperação energética. Disponível em 07 set 2018, em: <http://abrelpe.org.br/caderno-informativorecuperacao-energetica/>. Acesso em : 14 mar 2020.

ABRELPE. Panorama dos Resíduos Sólidos no Brasil. Disponível em: <http://abrelpe.org.br/panorama/>. 25-09-2018. Acesso em 06 out 2019.

ABRELPE. Panorama dos Resíduos Sólidos no Brasil 2017. São Paulo: ABRELPE, 2017. Disponível em: <http://abrelpe.org.br/download-panorama2017/>. Acesso em: 23 nov. 2020.

ABRELPE. Constituição (1988). Constituição da República Federativa do Brasil de 1988. Brasília, DF, Senado, 1988.

BURNLEY, S.J. A review of municipal solid waste composition in the United Kingdom. Waste Management, v. 27, n. 10, p. 1274-1282, 2007.

BURTON, I.; KATES, R. W.; WHITE, G. F. The environment as hazard. New York: Oxford University Press, 1978.

BRAGAGNOLO, L.; FERRAZZO, S.T.; BRUM, F.M.; KORF, E.P.; MOSSI, A.J. Composição gravimétrica e estimativa de geração per capita municipal de resíduos sólidos urbanos destinados ao Aterro Sanitário de Palmeira das Missões, RS, Brasil. Rev. Bras. Gest. Amb. Sustent. 2020, vol. 7, n. 16, p. 955. 
CARVALHO, M.L.F. Políticas de gestão dos resíduos sólidos domiciliares na cidade de Fortaleza- Ceará: avanços e desafios. Dissertação (Mestrado em Desenvolvimento e Meio Ambiente -PRODEMA, Universidade Federal da Paraíba, João Pessoa. 2016, 196f.:il. Acessível em: $<$ http://tede.biblioteca.ufpb.br:8080/handle/tede/9060>.

CASTRO, D.S.; MATEUS, V.O. Produção de biogás a partir de restos de alimentos coletados em um restaurante: uma experiência a ser disseminada. Seminário Estudantil de Produção Acadêmica, v. 15, 2016. Disponível em: $<$ https://revistas.unifacs.br/index.php/sepa/article/view/4355/3022>. Acesso em 09 jul 2020.

CENTRULO, N.M.; CENTRULO, T.B.; GONÇALVES DIAS, S.L.F.; RAMOS, T.B.Solid waste indicators in local sustainability assessment: a literature review. Revista Ambiente \& Sociedade. SciELO. São Paulo. Vol. 23, 2020.

CETESB, Companhia Ambiental do Estado de São Paulo. Termelétrica do Aterro Bandeirantes reduz emissão de C02 para a atmosfera. 2004. Disponível em : <https://cetesb.sp.gov.br/biogas/2004/03/25/termeletrica-doaterro-bandeirantes-reduz-emissao-de-co2-para-atmosfera/> . Acesso em 20. Jan. 2020.

CETESB, Companhia Ambiental do Estado de São Paulo. Energia a partir do lixo eleva potencial elétrico. mas não descarta hidrelétricas. Aterro Sanitário de Guatapará -São Paulo. Disponível em 07 set 2017: $<$ https://cetesb.sp.gov.br/biogas/2017/09/07/energia-a-partir-do-lixo-elevapotencial-eletrico-mas-nao-descarta-hidreleticas/>. Acesso em 26 out 2020.

CETESB, Companhia Ambiental do Estado de São Paulo. Câncer de pele aumenta em decorrência da incidência dos raios UV-B. Disponível em: $<$ https://cetesb.sp.gov.br/prozonesp/2018/12/12/cancer-de-pele-aumenta-emDecorrencia-da-incidencia-dos-raios-uv-b/>. 12 dez 2018. Acesso: 2 ago 2020.

CETESB, Companhia Ambiental do Estado de São Paulo. Biogás. Definição. Disponível em: <https://cetesb.sp.gov.br/biogas/>. Acesso em 24 out 2020.

CICLOVIVO, R. (17 de 4 de 2018). Fortaleza inaugura a maior usina de produção de biogás com lixo de aterro. Disponível em CICLOVIVO: $<$ https://ciclovivo.com.br/planeta/desenvolvimento/fortaleza-inaugura-maiorusina-produzir-biogas-com-lixo-de-aterro/>. Acesso em: 09 out 2019.

CICLOVIVO, R. Empresa gera biogás a partir de aterros sanitários e resíduos agrícolas. A Usina ZEG Biogás. Disponível em 23 set 2019: $<$ https://ciclovivo.com.br/planeta/energia/empresa-gera-biogas-aterrossanitarios-residuos-agricolas/>. Acesso em 25 out 2020.

COLAZO, A. B.; SÁNCHEZ, A.; FONT, X.; COLÓN, J. Environmental impact of rejected materials generated in organic fraction of municipal solid waste anaerobic digestion plants: Comparison of wet and dry process layout. Waste Management, v. 43, p. 84-97, 2015.

revista brasileira educação ambiental 
CONAMA. CONSELHO NACIONAL DO MEIO AMBIENTE. Resolução Conama n. 001/1986. Disponível em: $<$ http://www.mma.gov.br/port/conama/res/res86/res0186.html> Acesso: set de 2019.

CONAMA. Ministério do Meio Ambiente. Licenciamento Ambiental de Aterro Sanitário de pequeno porte de resíduos sólidos urbanos. CONAMA Resolução no 404/2008. 11 nov 2008. Disponível em: <http://www.mp.go.gov.br/portalweb/hp/9/docs/res conama 404 estabelece criterios e diretrizes para 0.pdf>. Acesso em:jun 2020.

DIÁRIO DO NORDESTE. Usina de biometano já planeja ampliar produção em 2019. 17 de abril de 2018. Disponível em: $<$ https://diariodonordeste.verdesmares.com.br/editorias/negocios/usina-debiometano-ja-planeja-ampliar-producao-em-2019-1.1924919> . Acesso em 06 out 2019

DIÁRIO DO NORDESTE. A energia que vem do lixo descartado e gera riqueza. 01/09/2018. Disponível em: $<$ https://www.diariodepernambuco.com.br/noticia/economia/2018/09/a-energiaque-vem-do-lixo-descartado-e-gera-riqueza.html>. Acesso em 06 out 2019.

ESMAEILIAN, B. et al. The future of waste management in smart and sustainable cities: A review and concept paper. Waste Management, v.81, p. 177-195, 2018.

EXAME. Revista. Interior de São Paulo ganha sua primeira usina movida a lixo. Usina de biogás de Guatapará. Disponível em 14 ago de 2014: $<$ https://exame.com/ciencia/interior-de-sp-ganha-sua-primeira-usina-movida-alixo/>. Acesso em 23 out 2020.

FORTALEZA. Plano Municipal de Gestão Integrada de Resíduos Sólidos Urbanos (PMGIRS). 2012.

FORTALEZA. Secretaria Municipal de Conservação e Serviços Públicos (SMCSP). Demonstrativo por produção geral de Resíduos Sólidos Domiciliares (RSD) gerado em toneladas ano, no município de Fortaleza, de janeiro a dezembro dos anos de 2014 a 2019.

GONÇALVES, P.V.S.; TAVARES, P.A.; FERREIRA, F.N.; DUTRA, V.A.B.; BELTRÃO, N.E.S.; FILHO, H.R.F.; RIBEIRO, H.M.C. Responsabilidade compartilhada sobre os resíduos sólidos e Educação Ambiental no contexto urbano amazônico. Revista Brasileira de Educação Ambiental, São Paulo, V. 14, №. 4: p. 360-373, 2019.

GUERRERO, L. A.; MAAS, G.; HOGLAND, W. Solid waste management challenges for cities in developing countries. Waste Management, v. 33, n. 1, p. 220-232, 2013.

IBGE. Instituto Brasileiro de Geografia e Estatística. Projeção e estimativa da população do Brasil e das Unidades da Federação. Disponível em: <https://www.ibge.gov.br/apps/populacao/projecao/> . Acesso em 05 out 2019. 
JORNAL O POVO. Revendas reajustam preço e gás de cozinha chega a $\mathbf{R} \$ 80$.

11 de fevereiro de 2019. Disponível em: $<$ https://www.opovo.com.br/jornal/economia/2019/02/31074-revendasreajustam-preco-e-gas-de-cozinha-chega-a-r--80.html>. Acesso em: 13 mai 2020.

MAGALHÃES, A.P.T. Biogás - Um projeto de saneamento urbano. São Paulo: Nobel, 1986.

MUYLAERT, M.S. Consumo de energia e aquecimento do planeta. Análise do Mecanismo de Desenvolvimento Limpo MDL do Protocolo de Quioto Estudos de Caso. Rio de Janeiro: Editora da Coppe, 2000.

PETROBRAS. Refinaria gera energia com biogás do Aterro Sanitário de Gramacho. Disponível em 29 mai 2014: <https://petrobras.com.br/fatos-edados/refinaria-gera-energia-com-biogas-do-aterro-de-gramacho.htm>. Acesso em: 25 out 2020 .

SÁNCHEZ, L. E. Avaliação de impacto ambiental: conceitos e métodos. São Paulo: Oficina de Textos, 2008. 495p.

SBERA. Sociedade Brasileira dos Especialistas em Resíduos das Produções Agropecuária e Agroindustrial (SBERA). (2015) ABNT deve definir neste mês norma para biometano. Concórdia. Disponível em: <Disponível em: <http://sbera.org.br/pt/2015/07/abnt-deve-definir-neste-mes-norma-parabiometano/>. Acesso em: 30 out 2020.

SEMACE. Superintendência Estadual do Meio Ambiente do Ceará .2019.

SOUZA, L. P.; OLIVEIRA, L. G.; REZENDE, F. M. Produção de biogás a partir do aproveitamento do chorume e vinhaça. 2019. Disponível em : $<$ https://www.saneamentobasico.com.br/wp-content/uploads/2019/08/producaobiogas-chorume-vinhaca.pdf>. Acesso em 09 jul 2020.

ZANETTI, I. Educação Ambiental, Resíduos Sólidos Urbanos e sustentabilidade. Um estudo de caso sobre o sistema de gestão de Porto Alegre-RS. Tese de Doutorado - Universidade de Brasília. Centro de Desenvolvimento Sustentável, 2003.

ZANETTI, I. Insustentabilidade e produção de resíduos: a face oculta do sistema do capital. Sociedade e Estado, Brasília, v. 24, n. 1, p. 173-192, jan./abr. 2009 